\title{
Young age increases risk for lymph node positivity but decreases risk for non-small cell lung cancer death
}

This article was published in the following Dove Press journal: Cancer Management and Research

\author{
Wenjie $\mathrm{Xia}^{1,2, *}$ \\ Anpeng Wang $1,2, *$ \\ Meng Jin ${ }^{3, *}$ \\ Qixing Mao',2 \\ Wenying $\mathrm{Xia}^{4}$ \\ Gaochao Dong' \\ Bing Chen ${ }^{1,2}$ \\ Weidong $\mathrm{Ma}^{1,2}$ \\ Lin $X u^{\prime}$ \\ Feng Jiang'
}

'Department of Thoracic Surgery, Nanjing Medical University Affiliated Cancer Hospital \& Jiangsu Cancer Hospital, Jiangsu Key Laboratory of Molecular and Translational Cancer Research, Cancer Institute of Jiangsu Province, ${ }^{2}$ Department of Oncology, Fourth Clinical College of Nanjing Medical University, Nanjing, ${ }^{3}$ Department of Gastroenterology,

Peking Union Medical College Hospital, Peking Union Medical College, Chinese Academy of Medical Sciences, Beijing, ${ }^{4}$ Department of Laboratory Medicine, The First Affiliated Hospital of Nanjing Medical University, Nanjing, People's Republic of China

*These authors contributed equally to this work

Correspondence: Lin Xu; Feng Jiang Department of Thoracic Surgery, Nanjing Medical University Affiliated Cancer Hospital, Jiangsu Key Laboratory of Molecular and Translational Cancer Research, Cancer Institute of Jiangsu Province, Baiziting 42, Nanjing 210009 ,

People's Republic of China

Tel +86 258328 4700; 862583283408

Fax +862583641062

Email xulin_83@hotmail.com;

zengnljf@hotmail.com

\begin{abstract}
Non-small cell lung cancer (NSCLC) prognosis and risk of lymph node positivity $(\mathrm{LN}+)$ are reference points for reasonable treatments. The aim of the current study was to investigate the effect of age on LN+ and NSCLC death. Data from the Surveillance, Epidemiology, and End Results (SEER) registry were used to identify 82,253 patients with NSCLC diagnosed between 1988 and 2008. All the patients underwent standard lung cancer surgery with lymph node examination. Demographic and clinicopathological parameters were extracted and compared among each age group. Impact of age on LN+ and NSCLC death was evaluated by the Cochran-Armitage trend test and logistic univariate and multivariate analyses for all $\mathrm{T}$ stages. Overall, 22,711 (27.60\%) patients of the entirety had lymph node metastasis and 28,968 $(35.22 \%)$ patients died of NSCLC within 5 years. With the increase in age, $\mathrm{LN}+$ rates decreased regardless of T stages $(P<0.001)$, whereas NSCLC-specific mortality increased in stages T1-T3 $(P<0.001)$. Controlling other covariates in multivariable logistic regression, age remained an independent risk factor for $\mathrm{LN}+$ in all $\mathrm{T}$ stages $(P<0.05)$ and in stages $\mathrm{T} 1-\mathrm{T} 3(P<0.05)$. Our SEER analysis demonstrated a higher rate of $\mathrm{LN}+$ and lower mortality in younger patients with NSCLC, after accounting for other covariates.
\end{abstract}

Keywords: NSCLC, lymph node positivity, mortality, age, SEER

\section{Introduction}

During clinical practice, we observed that young patients of non-small cell lung cancer (NSCLC) presented a higher rate of lymph node positivity (LN+). Some studies have shown this trend in melanoma and breast cancer. ${ }^{1-7}$ In contrast, $\mathrm{LN}+$ occurring in NSCLC by age groups is a poorly studied clinical entity.

NSCLC is increasingly understood as a heterogeneous disease, both in its clinical presentation and in its disease biology. Smoking is recognized as the main risk factor for NSCLC, and a higher incidence observed in older people may be due to the time required for the toxin to cause genetic aberrations that will ultimately lead to cancer. ${ }^{8,9}$ Therefore, it is logical that NSCLC in younger people presents different cancer behaviors, as also suggested by many published studies. ${ }^{8,10-13}$ However, there is still no definitive evidence on whether these cancer behaviors (including LN+) are unequivocally more aggressive in younger patients.

Despite the lack of consensus on NSCLC behaviors, recent studies tend to reach an agreement that younger age is associated with reduced NSCLC-related mortality. ${ }^{8,14,15}$ Since LN+ of NSCLC patients is undoubtedly indicative of poor prognosis, it would be paradoxical if young individuals show a higher $\mathrm{LN}+$ rate and a lower mortality in the meantime. 
For the current study, a large patient population was selected from the Surveillance, Epidemiology, and End Results (SEER) database, and their respective data were analyzed to investigate the impact of age on rate of $\mathrm{LN}+$ and NSCLC death.

\section{Materials and methods Case identification and data extraction}

Data from the SEER registry were obtained to identify 82,253 patients with NSCLC diagnosed from 1988 to 2008. The SEER program currently collects and publishes cancer incidence and survival data from population-based cancer registries covering $\sim 30 \%$ of the US population, and data accessed from the SEER database are freely available. ${ }^{16}$ The following criteria were applied to identify all eligible cases: 1) tumor with malignant behavior located in "lung and bronchus" (ICD-O-3/WHO 2008 site code C340-C343, C348-C349); however, patients with small cell lung cancer and other pathological types were excluded; 2) tumor diagnosed between January 1, 1988 and December 31, 2008 (patients diagnosed before 1988 were excluded because there was no specific staging information prior to 1988 , whereas patients diagnosed after 2008 were eliminated to ensure that we had adequate follow-up to evaluate 5-year mortality); 3 ) patients diagnosed by autopsy or reported only on a death certificate were excluded; 4) patients who received preoperation radiotherapy were excluded, to discharge the radiative effect on lymph node; 5) all patients received operation with lymph nodes examined, so patients who received local excision or local destruction were excluded because lymph node examination is not a standard demand in this procedure; and 6) patients without detailed information about $\mathrm{T}$ stage, pathological type, and surgery type were excluded.

Demographic and clinicopathological parameters were extracted using the "case listing" option. Cases were stratified by sex, race, age at diagnosis, SEER summary stage, pathological type, histologic grade, and type of surgery. The SEER summary stage was derived from collaborative stage (CS) for 2004+ and extent of disease (EOD) from 1973 to 2003. It is a simplified version of stage: localized, regional, distant, and unknown. We applied the SEER-modified American Joint Committee on Cancer (AJCC) stage for cases from 1988 to 2003 and the AJCC-derived T stage for cases after 2004.

\section{Measurements and statistical analysis}

We divided the patients according to the age with 10-year intervals; patients younger than 50 years were assigned to one group considering its small proportion. Chi-square analysis was used to compare proportions for all categorical data. Oneway analysis of variance (ANOVA) was used to compare the number of lymph node examined (LNE) among age groups. Cochran-Armitage trend tests were performed by Epi Info 7 to evaluate the impact of age on LN+ and NSCLC death. Logistic regression univariate analyses and multivariable analyses were performed for all $\mathrm{T}$ stages, targeting $\mathrm{LN}+$, and NSCLC-specific death as the outcomes. Age, sex, race, type of surgery, tumor grade, and pathological type were covariates. Results are represented in the form of odds ratios (ORs) with $95 \%$ confidence intervals (CIs). Age under 50 years was set as the reference group. Logistic regression analyses were performed with the SPSS v.19 statistical package.

Our work did not involve any human subjects or tissues or materials, the review and approval from a constituted review board were waived off.

\section{Results \\ Descriptive characteristics}

From 1988 to 2008, there were 82,253 patients with histologically confirmed NSCLC who met the inclusion criteria. Table 1 summarizes the demographic, tumor, and surgical characteristics. Females more frequently emerged in the $<50$-year-old group (55.13\%), whereas males more frequently emerged in the $>60$-year-old groups $(53.57 \%$ for group $60-69,53.58 \%$ for group $70-79$, and $52.57 \%$ for $\geq 80$ group). The greatest proportion was grade III (39.31\%) and T2 (46.41\%). The proportion of lung squamous cell carcinoma increased with the aging of patients $(17.12 \%$ in the $<50$-year-old group, $30.04 \%$ in the $\geq 80$-year-old group). Most of the patients underwent lobectomy (81.11\%), with $10.41 \%$ undergoing a partial/wedge/segment resection and the remaining $8.41 \%$ receiving complete/extended pneumonectomy. The proportion of patients who accepted partial/wedge/ segment resection or lobectomy increased $(7.25 \%-13.66 \%$ or $77.31 \%-82.63 \%$, respectively) with age, whereas the number of patients who accepted complete/extended pneumonectomy decreased $(15.44 \%-3.70 \%)$. The data of operation methods to some extent reveal that surgeons tended to take more radical treatments on younger patients.

In accordance with this tendency, within each $\mathrm{T}$ stage except T4, the average LNE decreases with the patients getting older (Table 2).

\section{Impact of age at diagnosis on $\mathrm{LN}+$ and mortality}

To explore differences in LN+ and NSCLC-specific mortality caused by age variance, we investigated divisions of patients 
Table I Demographic and clinicopathological characteristics by age at diagnosis

\begin{tabular}{|c|c|c|c|c|c|c|}
\hline \multirow[t]{2}{*}{ Characteristics } & \multirow[t]{2}{*}{ n (\%) } & \multicolumn{5}{|c|}{ Age at diagnosis, years (percent within age group) } \\
\hline & & $\leq 49$ & $50-59$ & $60-69$ & $70-79$ & $\geq 80$ \\
\hline \multicolumn{7}{|l|}{ Sex } \\
\hline Male & $43,190(52.51)$ & 44.87 & 50.45 & 53.57 & 53.58 & 52.57 \\
\hline Female & $39,063(47.5 \mathrm{I})$ & 55.13 & 49.55 & 46.43 & 46.42 & 47.43 \\
\hline \multicolumn{7}{|l|}{ Race } \\
\hline White & $70,674(85.91)$ & 76.65 & 81.17 & 85.55 & 88.71 & 90.78 \\
\hline Black & $6,722(8.21)$ & 15.53 & $12.4 \mathrm{I}$ & 8.80 & 5.60 & 3.62 \\
\hline Other & $4,785(5.8 I)$ & 7.62 & 6.29 & 5.57 & 5.62 & 5.58 \\
\hline Unknown & $72(0.11)$ & 0.21 & 0.13 & 0.08 & 0.07 & 0.01 \\
\hline \multicolumn{7}{|l|}{ Grade } \\
\hline I & $8,792(10.7 I)$ & 9.36 & 9.72 & 10.36 & 11.14 & 12.78 \\
\hline ॥ & $30,671(37.31)$ & 33.46 & 35.55 & 37.52 & 38.10 & 38.74 \\
\hline III & $32,339(39.31)$ & 41.53 & $4 I .4 I$ & 39.34 & 38.59 & 36.85 \\
\hline IV & $3,489(4.2 \mathrm{I})$ & 6.21 & 4.69 & 4.18 & 3.93 & 3.66 \\
\hline Unknown & $6,962(8.5 I)$ & 9.43 & 8.62 & 8.59 & 8.24 & 7.97 \\
\hline \multicolumn{7}{|l|}{ T stage } \\
\hline TI & 33,464 (40.7I) & 36.93 & 40.61 & 42.01 & 40.80 & 37.43 \\
\hline $\mathrm{T} 2$ & $38,180(46.4 I)$ & 46.27 & 44.94 & 45.31 & 47.03 & 51.13 \\
\hline T3 & $4,299(5.2 \mathrm{I})$ & 7.64 & 6.01 & 5.05 & 4.84 & 4.54 \\
\hline T4 & $6,310(7.71)$ & 9.16 & 8.44 & 7.63 & 7.32 & 6.89 \\
\hline \multicolumn{7}{|l|}{ Summary stage } \\
\hline Localized & $42,733(52.01)$ & 44.02 & 48.14 & 52.65 & 53.60 & 54.64 \\
\hline Regional & $37,023(45.01)$ & 51.40 & 48.09 & 44.43 & 43.70 & 42.84 \\
\hline Distant & $2,497(3.01)$ & 4.58 & 3.77 & 2.91 & $2.7 I$ & 2.52 \\
\hline \multicolumn{7}{|l|}{ Pathological type } \\
\hline Squamous cell & $24,135(29.31)$ & 17.12 & 23.61 & 30.14 & 32.93 & 30.04 \\
\hline Adenocarcinoma & $46,677(56.7 \mathrm{I})$ & 64.40 & 61.30 & 56.32 & 53.86 & 56.82 \\
\hline Others or NSCLC NOS & $|I, 44|(|3.9|)$ & 18.48 & 15.09 & 13.55 & 13.21 & 13.15 \\
\hline \multicolumn{7}{|l|}{ Surgery type } \\
\hline Partial/wedge/segment resection & $8,592(10.4 I)$ & 7.25 & 8.36 & 10.07 & 11.47 & 13.66 \\
\hline Lobectomy & $66,738(81.11)$ & 77.31 & 79.38 & 80.81 & 82.48 & 82.63 \\
\hline Complete/extended pneumonectomy & $6,923(8.4 I)$ & 15.44 & 12.26 & 9.11 & 6.05 & 3.70 \\
\hline \multicolumn{7}{|l|}{ Five-year status } \\
\hline Alive & $40,039(48.7 I)$ & 59.04 & 57.04 & 51.90 & 43.49 & 34.91 \\
\hline Lung cancer death & $28,968(35.21)$ & 33.16 & 33.10 & 34.00 & 36.75 & 39.02 \\
\hline Other deaths & $13,246(|6.1|)$ & 7.80 & 9.86 & 14.10 & 19.75 & 26.07 \\
\hline
\end{tabular}

Note: Characteristics compared using chi-square tests, all $P<0.001$.

Abbreviations: NSCLC, non-small cell lung cancer; NOS, not otherwise specified.

Table 2 Number of LNE stratified by age and stage

\begin{tabular}{|c|c|c|c|c|c|c|c|c|c|c|c|c|}
\hline \multirow{2}{*}{$\begin{array}{l}\text { Age, } \\
\text { years }\end{array}$} & \multicolumn{3}{|l|}{ TI } & \multicolumn{3}{|l|}{ T2 } & \multicolumn{3}{|l|}{ T3 } & \multicolumn{3}{|l|}{ T4 } \\
\hline & $\bar{n}$ & $\begin{array}{l}\text { Average } \\
\text { LNE }\end{array}$ & SE & $\bar{n}$ & $\begin{array}{l}\text { Average } \\
\text { LNE }\end{array}$ & SE & $\bar{n}$ & $\begin{array}{l}\text { Average } \\
\text { LNE }\end{array}$ & SE & $\bar{n}$ & $\begin{array}{l}\text { Average } \\
\text { LNE }\end{array}$ & SE \\
\hline All & 33,464 & 7.52 & 0.04 & 38,180 & 8.93 & 0.04 & 4,299 & 9.61 & 0.12 & 6,310 & 9.30 & 0.10 \\
\hline$\leq 49$ & 1,605 & 7.83 & 0.17 & 2,011 & 9.32 & 0.17 & 332 & 11.35 & 0.52 & 398 & 9.40 & 0.43 \\
\hline $50-59$ & 5,563 & 7.59 & 0.08 & 6,156 & 9.30 & 0.10 & 823 & 9.60 & 0.27 & 1,156 & 9.41 & 0.22 \\
\hline $60-69$ & I I,740 & 7.58 & 0.06 & $|2,66|$ & 9.09 & 0.07 & 1,410 & 9.78 & 0.22 & 2,132 & 9.43 & 0.18 \\
\hline $70-79$ & | I,868 & 7.49 & 0.06 & 13,680 & 8.72 & 0.06 & $\mathrm{I}, 408$ & 9.25 & 0.22 & 2,129 & 9.34 & 0.18 \\
\hline$\geq 80$ & 2,688 & 7.09 & 0.12 & 3,672 & 8.37 & 0.12 & 326 & 8.71 & 0.40 & 495 & 8.21 & 0.35 \\
\hline$P^{a}$ & $<0.001$ & & & $<0.001$ & & & $<0.001$ & & & 0.051 & & \\
\hline
\end{tabular}

Note: aP-value from the one-way ANOVA test.

Abbreviations: LNE, lymph node examined; SE, standard error; ANOVA, analysis of variance. 
according to $\mathrm{T}$ stage. Overall, 22,711 (27.60\%) patients had lymph node metastasis and 28,968 (35.22\%) died of NSCLC within 5 years. Regarding LN+, the percentage of patients with lymph node metastasis was $17.17 \%$ for T1 tumors, $32.71 \%$ for $\mathrm{T} 2$ tumors, $37.68 \%$ for $\mathrm{T} 3$ tumors, and $45.28 \%$ for T 4 tumors. Specific to each T stage, the rate of $\mathrm{LN}+$ reduced with the patients aging (all $P<0.001$; Table 3 ). Figure 1 presents the $\mathrm{LN}+$ rate grouped by age within $\mathrm{T}$ stage and number of LNE (median LNE=7). Within T stage and the LNE group, the inverse association between age and $\mathrm{LN}+$ remained statistically significant $(P<0.001)$.

In the matter of NSCLC death, the percentage of patients who died of NSCLC within 5 years was $24.47 \%$ for T1,
$39.38 \%$ for $\mathrm{T} 2,55.59 \%$ for $\mathrm{T} 3$, and $53.17 \%$ for $\mathrm{T} 4$. Within T1-T3 stages, NSCLC-specific mortality increased with the age of patients $(P<0.001$ for T1-T3; Table 4$)$. Figure 2 presents the NSCLC-specific mortality by age within T stage and number of LNE. Within T1-T3 stages, association between age and NSCLC-specific mortality remained statistically significant, stratified by LNE groups $(P<0.001)$.

\section{Regression analysis}

Logistic regression analysis was applied to assess whether the impact of age at diagnosis on LN+ and NSCLC mortality was independent of other factors. Sex, race, type of surgery, tumor grade, pathological type and number of LNE

Table $3 \mathrm{LN}+$ rate and age within T-stage groups

\begin{tabular}{|c|c|c|c|c|c|c|c|c|}
\hline \multirow{2}{*}{$\begin{array}{l}\text { Age, } \\
\text { years }\end{array}$} & \multicolumn{2}{|l|}{ TI } & \multicolumn{2}{|l|}{$\mathbf{T 2}$} & \multicolumn{2}{|l|}{ T3 } & \multicolumn{2}{|l|}{ T4 } \\
\hline & All patients & $\mathbf{L N}+(\%)$ & All patients & LN+ (\%) & All patients & $\mathbf{L N}+(\%)$ & All patients & LN+ (\%) \\
\hline All & 33,464 & $5,745(17.17)$ & 38,180 & $\mid 2,489(32.7 \mid)$ & 4,299 & $1,620(37.68)$ & 6,310 & $2,857(45.28)$ \\
\hline$\leq 49$ & $\mathrm{I}, 605$ & 394 (24.55) & 2,011 & $808(40.18)$ & 332 & $129(38.86)$ & 398 & $214(53.77)$ \\
\hline $50-59$ & 5,563 & I,I6I (20.87) & 6,156 & $2,341(38.03)$ & 823 & $358(43.50)$ & $\mathrm{I}, 156$ & $582(50.35)$ \\
\hline $60-69$ & $1 \mathrm{I}, 740$ & $2,008(17.10)$ & $|2,66|$ & $4,205(33.21)$ & 1,410 & $556(39.43)$ & 2,132 & $986(46.25)$ \\
\hline $70-79$ & 11,868 & I,833 (I5.44) & 13,680 & 4,161 (30.42) & $\mathrm{I}, 408$ & 477 (33.88) & 2,129 & $878(4 \mid .24)$ \\
\hline$\geq 80$ & 2,688 & 349 (12.98) & 3,672 & $974(26.53)$ & 326 & $100(30.67)$ & 495 & $197(39.80)$ \\
\hline$P^{a}$ & $<0.001$ & & $<0.001$ & & $<0.001$ & & $<0.001$ & \\
\hline
\end{tabular}

Note: ${ }^{\text {P}}$-value from the Cochran-Armitage trend test.

Abbreviation: $\mathrm{LN}+$, lymph node positive.

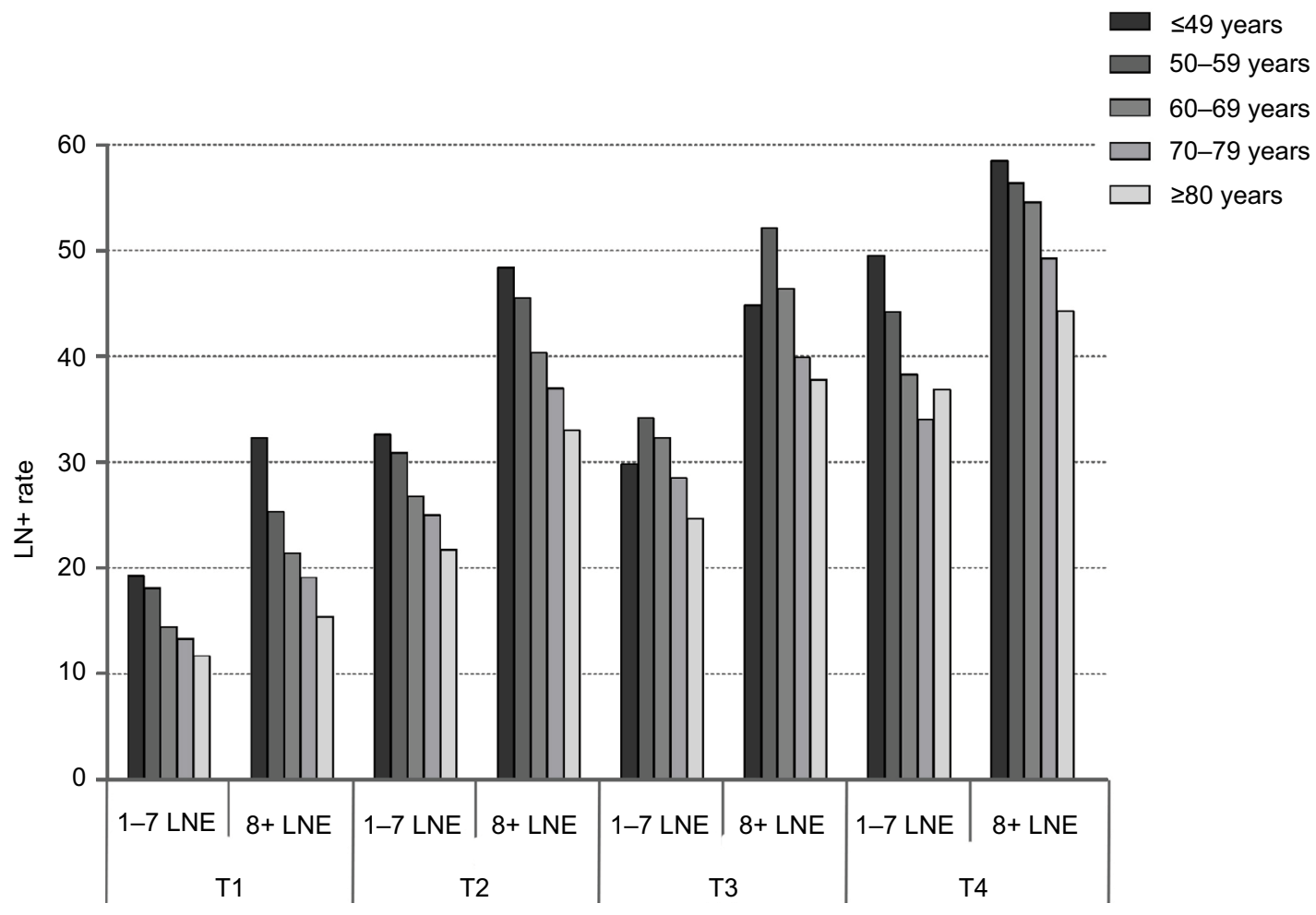

Figure I Impact of age on LN+ by T stage and LNE.

Abbreviations: LN+, lymph node positivity; LNE, lymph node examined. 
Table 4 Lung cancer-specific mortality and age within T-stage groups

\begin{tabular}{|c|c|c|c|c|c|c|c|c|}
\hline \multirow{2}{*}{$\begin{array}{l}\text { Age, } \\
\text { years }\end{array}$} & \multicolumn{2}{|l|}{ TI } & \multicolumn{2}{|l|}{ T2 } & \multicolumn{2}{|l|}{ T3 } & \multicolumn{2}{|l|}{ T4 } \\
\hline & All patients & Dead (\%) & All patients & Dead (\%) & All patients & Dead (\%) & All patients & Dead (\%) \\
\hline$\overline{\text { All }}$ & 33,464 & $8,187(24.47)$ & 38,180 & $15,037(39.38)$ & 4,299 & $2,390(55.59)$ & 6,310 & $3,354(53.17)$ \\
\hline$\leq 49$ & 1,605 & $358(22.3 \mathrm{I})$ & 2,011 & $716(35.61)$ & 332 & 156 (46.99) & 398 & $211(53.02)$ \\
\hline $50-59$ & 5,563 & I,208 (2I.7I) & 6,156 & $2,303(37.4 I)$ & 823 & $417(50.67)$ & $\mathrm{I}, 156$ & $606(52.42)$ \\
\hline $60-69$ & $\mathrm{II}, 740$ & $2,750(23.42)$ & $|2,66|$ & $4,888(38.61)$ & 1,410 & $765(54.26)$ & 2,132 & $\mathrm{I}, 098(5 \mathrm{I} .50)$ \\
\hline 70-79 & 11,868 & $3,090(26.04)$ & 13,680 & $5,592(40.88)$ & $\mathrm{I}, 408$ & $845(60.01)$ & 2,129 & $\mathrm{I}, \mathrm{I} 63$ (54.63) \\
\hline$\geq 80$ & 2,688 & 781 (29.06) & 3,672 & I,538 (4I.88) & 326 & $207(63.50)$ & 495 & $276(55.76)$ \\
\hline $\mathrm{pa}$ & $<0.001$ & & $<0.001$ & & $<0.001$ & & 0.104 & \\
\hline
\end{tabular}

Note: a $P$-value from the Cochran-Armitage trend test.

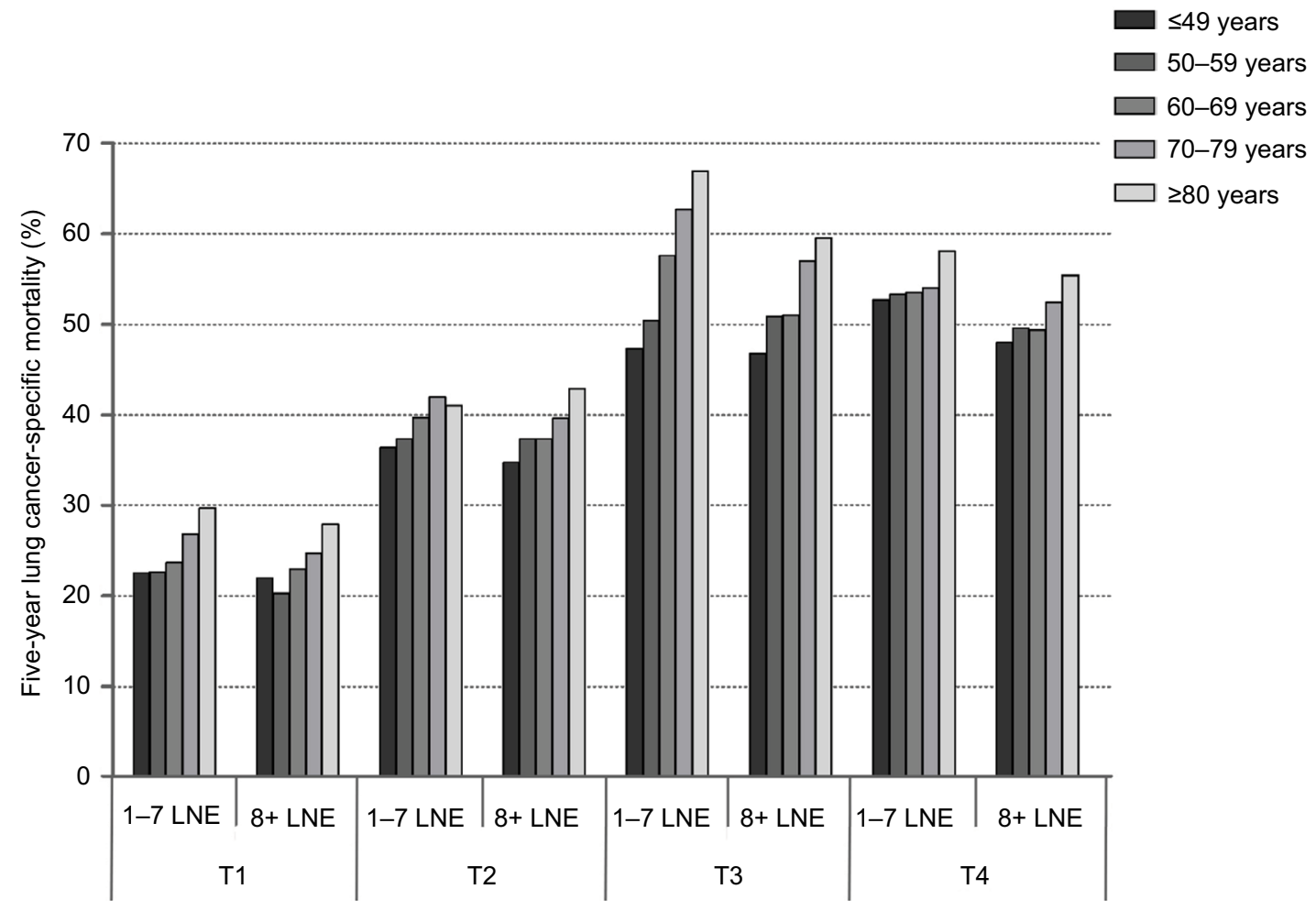

Figure 2 Impact of age on NSCLC-specific mortality by T stage and LNE.

Abbreviations: NSCLC, non-small cell lung cancer; LNE, lymph node examined.

were in the adjusted model as covariates. Age remained a significant risk factor of $\mathrm{LN}+$ for all $\mathrm{T}$ stages and mortality for T1-T3 stages after controlling for covariates (Tables 5 and 6). Patients older than 80 years were less likely to present $\mathrm{LN}+$ in comparison to the reference group ( $\leq 50$ years), with adjusted $\mathrm{ORs}$ of $\mathrm{T} 1$ ( $\mathrm{OR}=0.51,95 \% \mathrm{CI}=0.44-0.60)$, $\mathrm{T} 2(\mathrm{OR}=0.65,95 \% \mathrm{CI}=0.57-0.73)$, and $\mathrm{T} 4(\mathrm{OR}=0.69,95 \%$ $\mathrm{CI}=0.52-0.90)$. We noticed that in stage $\mathrm{T} 3$, the oldest group showed a nonsignificant OR with $95 \% \mathrm{CI}(\mathrm{OR}=0.94,95 \%$ $\mathrm{CI}=0.67-1.31$ ) compared to the youngest group, which may be attributed to the relatively small sample size (355 patients under age of 50 years in T3 stage). We deemed that the $P$ value (0.009) was rational as it was calculated within the whole $\mathrm{T} 3$ stage from logistic regression analysis.
The inverse correlation was seen on mortality for stages T1-T3, while patients older than 80 years showed a higher mortality compared with the reference age group, with adjusted ORs of $11(\mathrm{OR}=1.39,95 \% \mathrm{CI}=1.20-1.60), \mathrm{T} 2(\mathrm{OR}=1.38,95 \%$ $\mathrm{CI}=1.24-1.55)$, and $\mathrm{T} 3(\mathrm{OR}=2.00,95 \% \mathrm{CI}=1.46-2.75)$.

\section{Discussion}

Multiple factors were proved to impact the risk of $\mathrm{LN}+$ in NSCLC such as T stage and histologic grade. ${ }^{17-20}$ However, until now, there has been no study investigating the predictive role of age for LN+ in NSCLC patients. In this study of large sample, we demonstrated that younger patients have a higher incidence of lymph node metastasis compared to older individuals, despite a lower incidence of NSCLC death. 

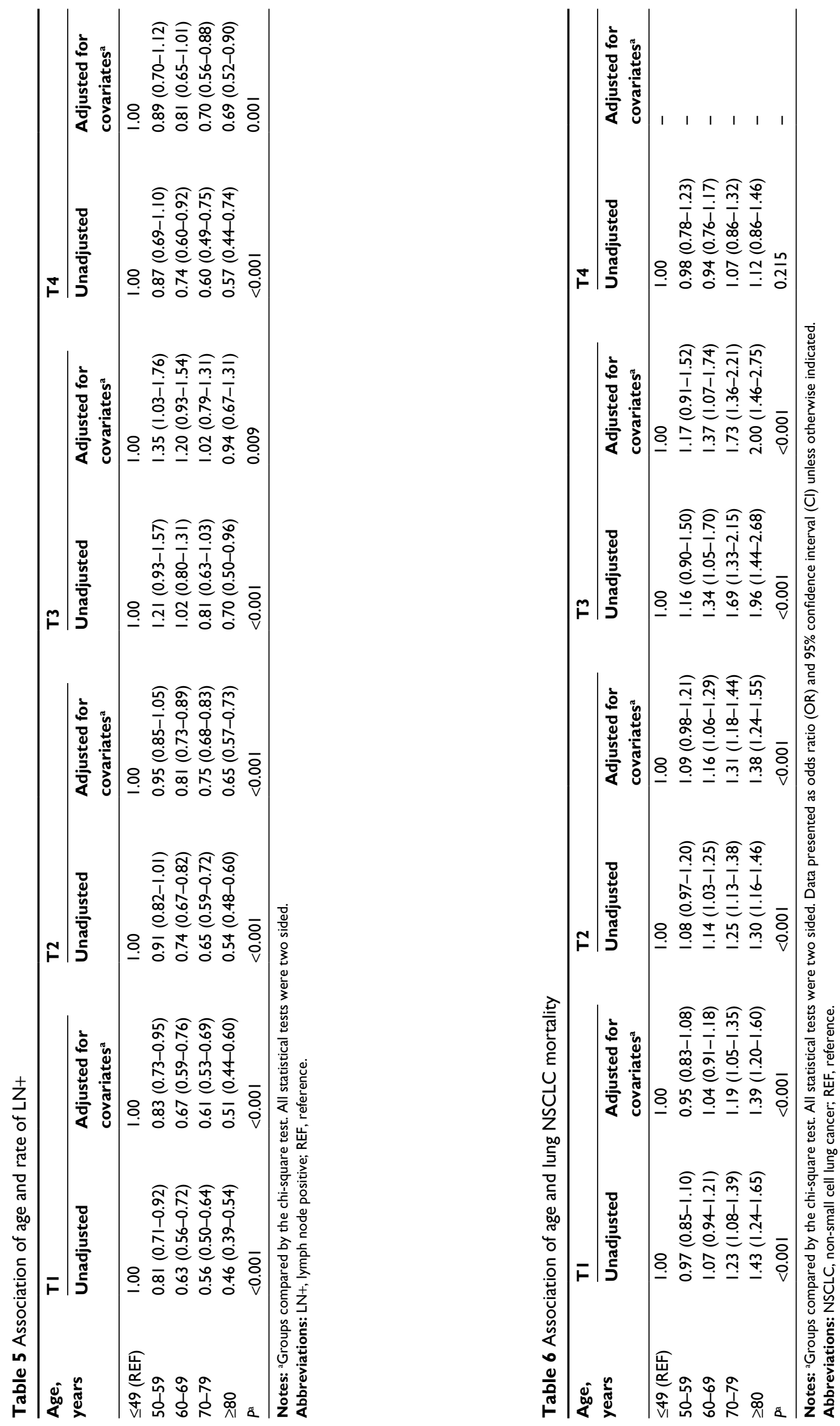
One possible explanation for the effect of age on $\mathrm{LN}+$ is that there is a biological difference in NSCLC of younger patients. Previous studies proved that adenocarcinoma is more common and squamous cell carcinoma is less common in the younger group..$^{8,9,12,21-25}$ This may reflect both a lower smoking prevalence and duration of exposure to tobacco smoke in this age group, resulting in decreased incidence of tumor types most closely linked with smoking. ${ }^{26,27}$ In our study, we confirmed that young patients were more frequently females who have different smoking habits (fewer smokers). From the view of genomic makeup, a recent study revealed that younger age is associated with an increased likelihood of harboring a targetable genotype, which is an underappreciated clinical biomarker in NSCLC. ${ }^{28}$ In addition, elder patients have weaker immunologic function in contrast with younger individuals. Several studies supported that there are age-dependent variations on cancer immune surveillance, including reduced lymphatic flow to nodes and nodal involution. ${ }^{29}$

We found evidence that mortality was lower in the young adult group overall, in contrast to some published data ${ }^{10,24,30,31}$ but in agreement with others. , $^{814,15,21,32,33}$ Apparently, older patients are sicker with a higher risk of multiple cardiac and respiratory comorbidities. However, the use of the parameter NSCLC-specific mortality mainly excluded this selection bias of patients in the current study. It is reported that younger patients are more likely to undergo more complete, radical, aggressive, and combination treatment modalities than older patients, which is also reflected by our data. ${ }^{11,13,34}$ According to our clinical practice, the higher rate of neo-adjuvant and adjuvant therapies in the young group could reflect not only the higher percentage of advanced stages but also the ability of young patients to better tolerate multimodality treatment.

The paradox of a high rate of $\mathrm{LN}+$ and low mortality in younger patients highlights the need for further investigation into age-related differences in NSCLC biology, immunological surveillance, and host response. Additionally, in the elderly, other miscellaneous factors such as limited physiologic reserve, poor access to care, and potential physician inclination toward less aggressive interventions should be studied.

Clinically, accurate prediction of lymph node involvement is essential in helping surgeons make decisions more reasonably. Lymph node status could impact the treatment recommendations for a patient with NSCLC. For example, neoadjuvant chemoradiotherapy would only be administered for early T-stage patients with lymph node metastasis. Underestimating the risk for $\mathrm{LN}+$ would lead to lack of neoadjuvant chemoradiotherapy, followed by an increased rate of recurrence and toxicity. In view of the higher rate of LN+ in younger patients, we suggest that young NSCLC patients receive a thorough and professional assessment of lymph node-bearing regions before surgical treatment. In addition, as wedge/segment resection examines and removes fewer lymph nodes than radical lobectomy, surgeons should seriously take wedge/segment resection for younger patients with early stage disease according to these data.

It should be noted that although we used a considerable size of sample from the SEER registries to prove that younger patients have a higher incidence of lymph node metastasis and a lower incidence of NSCLC death compared to older individuals, the study was limited by the fact that the data reflected only selected SEER areas and were not applicable to other geographic locations. Lack of data on chemotherapy and other adjuvant treatments, smoking status, and comorbidities were also limitations of this study. In addition, as a retrospective study, unmeasured selection bias enters into the research inevitably and limits interpretation.

In summary, our SEER analysis demonstrated higher rates of $\mathrm{LN}+$ and lower mortality in young patients with NSCLC, after accounting for other predictive factors. The results could influence the aggressiveness of nodal staging in younger patients with NSCLC and highlight the need for further investigation.

\section{Acknowledgment}

This research was supported by the National Natural Science Foundation of China (No. 81672294) and the Natural Science Foundation of Jiangsu Province (grant no. SBK016030028).

\section{Disclosure}

The authors report no conflicts of interest in this work.

\section{References}

1. Macdonald JB, Dueck AC, Gray RJ, et al. Malignant melanoma in the elderly: different regional disease and poorer prognosis. J Cancer. 2011;2:538-543.

2. Chao C, Martin RC, Ross MI, et al. Correlation between prognostic factors and increasing age in melanoma. Ann Surg Oncol. 2004;11(3): 259-264.

3. Paek SC, Griffith KA, Johnson TM, et al. The impact of factors beyond Breslow depth on predicting sentinel lymph node positivity in melanoma. Cancer. 2007;109(1):100-108.

4. Page A, Li A, Hestley A, Murray D, Carlson G, Delman K. Increasing age is associated with worse prognostic factors and increased distant recurrences despite fewer sentinel lymph node positives in melanoma. Int J Surg Oncol. 2012;2012:456987.

5. Statius Muller MG, van Leeuwen PA, de Lange-de Klerk ES, et al. The sentinel lymph node status is an important factor for predicting clinical outcome in patients with stage I or II cutaneous melanoma. Cancer. 2001;91(12):2401-2408. 
6. Mamounas EP. Age and lymph node status in breast cancer: not a straightforward relationship. J Clin Oncol. 2009;27(18):2900-2901.

7. Caywood J, Gray RJ, Hentz J, Pockaj BA. Older age independently predicts a lower risk of sentinel lymph node metastasis in breast cancer. Ann Surg Oncol. 2005;12(12):1061-1065.

8. Subramanian J, Morgensztern D, Goodgame B, et al. Distinctive characteristics of non-small cell lung cancer (NSCLC) in the young: a surveillance, epidemiology, and end results (SEER) analysis. J Thorac Oncol. 2010;5(1):23-28.

9. Kreuzer M, Kreienbrock L, Gerken M, et al. Risk factors for lung cancer in young adults. Am J Epidemiol. 1998;147(11):1028-1037.

10. Bryant AS, Cerfolio RJ. Differences in outcomes between younger and older patients with non-small cell lung cancer. Ann Thorac Surg. 2008;85(5):1735-1739.

11. Liam C-K, Lim K-H, Wong CM-M. Non-small cell lung cancer in very young and very old Malaysian patients. Chest J. 2002;121(1):309-310.

12. Mauri D, Pentheroudakis G, Bafaloukos D, et al; Hellenic Cooperative Oncologic Group (HeCOG). Non-small cell lung cancer in the young: a retrospective analysis of diagnosis, management and outcome data. Anticancer Res. 2006;26(4B):3175-3181.

13. Inoue $M$, Okumura $M$, Sawabata $N$, et al. Clinicopathological characteristics and surgical results of lung cancer patients aged up to 50 years: the Japanese Lung Cancer Registry Study 2004. Lung Cancer. 2014;83(2):246-251.

14. Dell'Amore A, Monteverde M, Martucci N, et al. Surgery for non-small cell lung cancer in younger patients: what are the differences? Heart Lung Circ. 2015;24(1):62-68.

15. Rich AL, Khakwani A, Free CM, et al. Non-small cell lung cancer in young adults: presentation and survival in the English National Lung Cancer Audit. QJM. 2015;108(11):891-897.

16. National Cancer Institute [homepage on the Internet]. The Surveillance, Epidemiology, and End Results (SEER) Program. Available from: www. seer.cancer.gov. Accessed December 12, 2017.

17. Zang R-C, Qiu B, Gao S-G, He J. A model predicting lymph node status for patients with clinical stage T1aN0-2M0 nonsmall cell lung cancer. Chin Med J. 2017;130(4):398.

18. Xiong J, Wang R, Sun Y, Chen H. Clinical analysis of sixty-four patients with T1aN2M0 stage non-small cell lung cancer who had undergone resection. Thorac Cancer. 2015;7(2):215-221.

19. Zhang Y, Sun Y, Xiang J, Zhang Y, Hu H, Chen H. A prediction model for N2 disease in T1 non-small cell lung cancer. J Thorac Cardiovasc Surg. 2012;144(6):1360-1364.
20. Shafazand S, Gould MK. A clinical prediction rule to estimate the probability of mediastinal metastasis in patients with non-small cell lung cancer. J Thorac Oncol. 2006;1(9):953-959.

21. Minami H, Yoshimura M, Matsuoka H, Toshihiko S, Tsubota N. Lung cancer treated surgically in patients $<50$ years of age. Chest. 2001;120(1):32-36.

22. Bourke W, Milstein D, Giura R, et al. Lung cancer in young adults. Chest. 1992;102(6):1723-1729.

23. Lienert T, Serke M, Schonfeld N, Loddenkemper R. Lung cancer in young females. Eur Respir J. 2000;16(5):986-990.

24. Jiang W, Kang Y, Shi G, et al. Comparisons of multiple characteristics between young and old lung cancer patients. Chin Med J. 2012;125(1): 72-80.

25. Kreuzer M, Wichmann H. Lung cancer in young females. Eur Respir J. 2001;17(6):1333-1333.

26. Peto R, Darby S, Deo H, Silcocks P, Whitley E, Doll R. Smoking, smoking cessation, and lung cancer in the UK since 1950: combination of national statistics with two case-control studies. $B M J$. 2000;321(7257):323-329.

27. Alberg AJ, Ford JG, Samet JM. Epidemiology of lung cancer: ACCP evidence-based clinical practice guidelines. Chest J. 2007;132(suppl 3): 29S-55S.

28. Sacher AG, Dahlberg SE, Heng J, Mach S, Jänne PA, Oxnard GR. Lung cancer diagnosed in the young is associated with enrichment for targetable genomic alterations and poor prognosis. JAMA Oncol. 2016;2(3):313.

29. Pan W-R, Suami H, Taylor GI. Senile changes in human lymph nodes. Lymphat Res Biol. 2008;6(2):77-83.

30. Antkowiak JG, Regal A-M, Takita H. Bronchogenic carcinoma in patients under age 40. Ann Thorac Surg. 1989;47(3):391-393.

31. Green LS, Fortoul TI, Ponciano G, Robles C, Rivero O. Bronchogenic cancer in patients under 40 years old: the experience of a Latin American country. Chest. 1993;104(5):1477-1481.

32. Liu NS, Spitz MR, Kemp BL, et al. Adenocarcinoma of the lung in young patients. Cancer. 2000;88(8):1837-1841.

33. Lara MS, Brunson A, Wun T, et al. Predictors of survival for younger patients less than 50 years of age with non-small cell lung cancer (NSCLC): a California Cancer Registry analysis. Lung Cancer. 2014;85(2): 264-269.

34. Aggarwal C, Langer CJ. Older age, poor performance status and major comorbidities: how to treat high-risk patients with advanced nonsmall cell lung cancer. Curr Opin Oncol. 2012;24(2):130-136.
Cancer Management and Research

\section{Publish your work in this journal}

Cancer Management and Research is an international, peer-reviewed open access journal focusing on cancer research and the optimal use of preventative and integrated treatment interventions to achieve improved outcomes, enhanced survival and quality of life for the cancer patient. The manuscript management system is completely online and includes

\section{Dovepress}

a very quick and fair peer-review system, which is all easy to use. Visit http://www.dovepress.com/testimonials.php to read real quotes from published authors. 